\title{
The role of discourse context in developing word form representations: A paradoxical relation between reading and learning
}

\author{
Nicole Landi ${ }^{\text {a,* }}$, Charles A. Perfetti ${ }^{\text {a }}$, Donald J. Bolger ${ }^{\text {a }}$, \\ Susan Dunlap ${ }^{\mathrm{a}}$, Barbara R. Foorman ${ }^{\mathrm{b}}$ \\ a Department of Psychology, Learning Research and Development Center and \\ Center for the Neural Basis of Cognition, University of Pittsburgh, Pittsburgh, PA 15260, USA \\ ${ }^{\mathrm{b}}$ Department of Pediatrics, University of Texas-Houston Health Science Center, Houston, TX 77030, USA
}

Received 27 October 2003; revised 14 December 2005

Available online 4 April 2006

\begin{abstract}
To acquire representations of printed words, children must attend to the written form of a word and link this form with the word's pronunciation. When words are read in context, they may be read with less attention to these features, and this can lead to poorer word form retention. Two experiments with young children (ages 5-8 years) confirmed this hypothesis. In our experiments, children attempted to read words they could not previously read, during a self-teaching period, either in context or in isolation. Later they were tested on how well they learned the words as a function of selfteaching condition (isolation or context). Consistent with previous research, children read more words accurately in context than in isolation during self-teaching; however, children had better retention for words learned in isolation. Furthermore, this benefit from learning in isolation was larger for less skilled readers. This effect of poorer word retention when words are learned in context is paradoxical because context has been shown to facilitate word identification. We discuss factors that may influence this effect of context, especially the role of children's skill level and the demands of learning new word representations at the beginning of reading instruction.
\end{abstract}

(c) 2005 Elsevier Inc. All rights reserved.

\footnotetext{
* Corresponding author. Present address: Haskins Laboratories, New Haven, CT 06511, USA. Fax: +1 203865 8963.

E-mail address: landi@haskins.yale.edu (N. Landi).
} 


\section{Introduction}

How do children develop unified orthographic and phonological representations for specific words? Although substantial research has addressed the nature of adult word form representations, ${ }^{1}$ relatively little work has examined the course of development of these representations (Rayner, Foorman, Perfetti, Pesetsky, \& Seidenberg, 2001). A search of the reading literature revealed more than three times as many articles about adult word representations as those about children building these representations. Of course, many studies have targeted other questions about children's reading, including comparisons of instructional methods and effects of phonological awareness on early literacy. However, the more specific question of how children acquire specific word form representations has received little attention. Thus, many critical questions remain unanswered. How do children's word form representations change during the course of reading development? How do the word form representations of skilled and less skilled readers differ? How do children access word form representations during encounters with print? What factors influence the learning of new word form representations?

Research by Ehri and colleagues (Ehri, 1991; Ehri \& Wilce, 1985), by Share and colleagues (Cunningham, Perry, Stanovich, \& Share, 2002; Share, 1995, 1999), and by Reitsma (1983) illustrated some partial answers to these questions. Ehri and Wilce (1985) demonstrated that during the earliest stages of learning to read, children with little or no ability to read words use the names of letters as phonological cues to recall words. This implies that phonological representations can be linked to orthographic representations from the beginning and that these phonological representations assist in forming orthographic representations (children's knowledge of a specific spelling that connects to a representation in their phonological lexicon), thereby creating a unified form (letter and sound) representation. Form representations of larger units (i.e., words) are assumed to develop in part through encounters with specific words and in part through the generalization of letterphoneme connections across large portions of the lexicon (Perfetti, 1992; Share, 1995). This idea is supported by the work of Reitsma (1983), who showed that young Dutch children learn about the orthographic forms of words quickly and that their knowledge includes information about specific letter patterns. His work suggested that knowing where specific letters are likely to occur, and that certain letter combinations are predictable, is one way in which children learn to generalize when learning new orthographic forms. Share's (1995) self-teaching hypothesis outlined another way in which young readers might learn new word form representations. According to the self-teaching hypothesis, children use the knowledge of letter-sound correspondences during an encounter with a printed word to first decode the word and then, by feedback to the letters, begin to establish an orthographic representation of the word that reinforces the phonological representation.

\footnotetext{
${ }^{1}$ Unless otherwise specified, we use the term form throughout this article to indicate both orthographic information and the mappings between orthographic and phonological information. We use this term to distinguish this type of knowledge from vocabulary knowledge, and it should not be confused with pure orthographic form (letters only).
} 
Consistent with Share and Ehri, our hypothesis is that acquiring word form representations depends on attending to the letters of a word and their corresponding sounds sufficiently to establish the spelling and pronunciation of a word. This representation can then be used to read the word on later encounters. We further hypothesize that the way in which children learn new words can influence how much attention is given to word forms. Specifically, we posit that learning new words in a semantic context may draw attention away from word forms, thereby decreasing the likelihood that a lasting form representation will be established.

The effects of context on word reading have been well studied. In the ordinary case, context provides meaning that helps to support the identification of a word (Nation \& Snowling, 1998; Roth \& Perfetti, 1980; Schwantes, Boesl, \& Ritz, 1980; Stanovich, Nathan, West, \& Vala-Rossi, 1985). However, we suggest that when children do not have a good orthographic and phonological representation for a word, or when their representation is just beginning to be established, the effects of context may be more complex. For example, context may bring support for identification of an unfamiliar word, but it may also fail to support the establishment of a new word form. Our hypothesis does not contradict the well-known positive effects of context on word identification. These positive effects are restricted to the identification of a word, whereas our hypothesized negative effects are restricted to the learning of a new word form. That is, because context adds activation to a word's representation in memory, it supports successful identification of a word without full processing of the word's form (i.e., the word need not be fully decoded in a bottom-up fashion). We predict that the asymmetrical benefit of context (facilitative for word reading but not for form learning) is more likely to occur for readers who are both unfamiliar with the word being read and have relatively few fully specified orthographic and phonological representations. For readers with more fully specified representations, the effects of context may be facilitative for both identification and learning because their decoding knowledge allows them a more effective distribution of attention and resources when they encounter an unfamiliar word; that is, they can "afford" to allocate more attention to meaning (i.e., context) and less to decoding.

A recent experiment by Archer and Bryant (2001) compared children's reading of unknown words in and out of context. They identified words that 6- and 7-year-olds were unable to read in isolation. They then presented (aurally) these words to the children either in a sentence context or in isolation, gave them feedback on their performance, and later tested them on their ability to read those same words in isolation. The children were able to read the words more accurately when they were presented in context, but they were no better at reading these words when they were presented later in isolation on the posttest. That is, the children improved on both the words read in isolation and the words read in context to the same extent.

Although these findings demonstrate that context is not helpful for the formation of lasting word form representations, Archer and Bryant's (2001) experiment was not designed to test whether context may actually be problematic for word form learning under certain conditions or how context would affect word learning for different types of readers. Because feedback was provided in both isolated and contextualized learning conditions, the differences between the context and isolation conditions that normally would favor isolated learning would have been reduced in their experiment. Children normally would need to struggle with unknown isolated forms (relative to the contextualized forms), making the representation stronger in the case where the word is successfully decoded in 
isolation. Providing feedback may have diminished differences between context and isolation because children were not required to struggle with difficult words if they knew they would always be given the answers. Furthermore, providing the correct pronunciation may have also reduced individual differences in children's ability to decode items and, hence, differences in word learning.

On our account of word form acquisition, the feedback that promotes the formation of a lasting orthographic and phonological form representation is the association between readers' generated phonology and the letters that are being attended to simultaneously. This process can operate both in context and in isolation, although in our hypothesis its effectiveness depends on attention to the letters and their corresponding pronunciation, which may be weakened in context. We hypothesize that it is this difference in attention that leads to the asymmetric effects of context; therefore, it is important to preserve the differences between isolated learning and contextualized learning (by not providing feedback) to detect the effect. Furthermore, when comparing differences between learning in context and learning in isolation, the type of analysis that is conducted on posttest reading is critical. Previous studies (e.g., Archer \& Bryant, 2001) employed a simple analysis that compared only the number of items read correctly on the posttest as a function of training condition without consideration of whether or not the words were decoded correctly during training. This simple comparison of isolated word reading performance as a function of self-teaching in context versus self-teaching in isolation is not sufficient. Children are more likely to read words correctly in context; thus, they get greater motor and auditory feedback from saying the correct items. According to Share (1999), both seeing and saying the word contribute to how well the item will be learned. Therefore, a conditional analysis comparing word retention - not simple word reading - is required. That is, the final analysis should include a comparison of posttest performance on only those words that eventually were learned (pronounced correctly) during training - a word retention analysis.

We report two experiments that were designed to test the hypothesized relation between the effect of context during reading and the effect of context on learning new words. In our first experiment, children read unknown target words aloud, either in context or in isolation, without instructor feedback and were later tested on how well they learned the new words. Our "untutored learning" design maximizes the similarity to a natural reading situation and, as such, provides a fair comparison between isolated word reading and contextualized word reading.

In our second experiment, we again used the untutored learning design but increased the number of encounters with a word from one to three during self-teaching for both in context encounters and in isolation encounters. In addition, we examined the effect of learning a word in three different contexts across self-teaching as compared with just one context. These manipulations provided a test of our hypothesis in an even more naturalistic learning environment.

These two experiments were designed specifically to compare the formation of new and lasting word representations for words learned in context with that for words learned in isolation. Therefore, to assess word learning, we tracked the fate of each previously unknown word as it was read successfully, in or out of context, on a first occasion and whether it was retained over the next few days. Thus, the key posttest comparison in our experiments concerns retention of those words that were read successfully during the selfteaching session. 
Furthermore, in both experiments, we examined the affect of reading skill on acquisition of new word representations. Children's comprehension and decoding abilities can vary, thereby affecting their ability to acquire new representations. Skill level may also lead to differences in the use of context to learn new representations. If our hypothesis is correct, context will have its most asymmetrical effects between word reading and word learning on less skilled readers. These children, because they have poorly developed decoding skill, may rely more on context for bootstrapping. If so, they may fail to attend to a word's orthographic and phonological representation and therefore will not properly encode the information required to form a lasting representation. More skilled readers, whose greater knowledge of word forms and better decoding skill allow a more effective distribution of attention and resources between form and meaning, may be more likely to encode the relevant orthographic and phonological representations when reading new words in context.

\section{Experiment 1}

Experiment 1 compared more skilled and less skilled first and second graders' ability to retain newly learned words as a function of whether they were learned in isolation or in context.

\section{Method}

\section{Participants}

The original sample consisted of 43 first and second graders ( 24 girls and 19 boys) from an ethnically mixed elementary school in Pittsburgh, Pennsylvania, with most children coming from middle-class homes. The mean age of the children was 6.96 years. Of the original 43 students, 20 did not make it through the final phase of the experiment because they read above the second-grade level, did not complete the experiment due to absences, or moved during the testing period. A total of 23 students participated in the entire experiment (14 girls and 9 boys, mean age $=6.81$ years, $S D=0.40$ year).

\section{Procedure}

Each child was tested individually in four separate sessions. The first session assessed the child's reading ability, the second session identified a set of words the child was unable to read in isolation (the learning set), the third session required the child to read half the words in the learning set in context and half in isolation (words were randomly assigned to condition), and the fourth session required the child to read the words in the learning set once more in isolation (presented in random order).

\section{Session 1: Reading assessment}

To assess children's reading skill, an abbreviated version of the word reading portion of the Wide Range Achievement Test (WRAT) was administered to each child individually. This test consists of isolated words of increasing difficulty that are read aloud in succession. This assessment set provided two scores: a word reading score based on the percentage correct of 15 total possible words and a reading grade based on the difficulty of the words 
that the child was able to read. Any child who read above the second-grade level was removed from the sample to reduce potential ceiling effects. In addition, we included a nonword reading test that consisted of 9 pronounceable and orthographically legal nonwords varying in length from three to six letters. Each child's nonword reading score was calculated as a percentage read correctly of 9 total possible words.

\section{Session 2: Pretest}

Based on their WRAT scores, children were presented with a list of words matched to their reading ability (see details presented subsequently). The list contained 82 words that were presented in bold black ink on a white paper background. During the pretest, the child received no feedback; his or her pronunciations of words were recorded by a cassette tape-recorder and written down by the experimenter on a scoring sheet that the child could not see. Words not read correctly during this session became the child's learning set for the next session. The pretest was used only to assess the child's knowledge of the presented words. This test was used to equate all of the children on their knowledge of words. That is, only words that were unfamiliar to a child were presented to him or her later in the selfteaching session. Thus, children were compared on their reading performance for different words; however, this was necessary because different children have different word knowledge, and we needed to ensure that each child was trained on words with which he or she was unfamiliar.

Pretest words. The words given to the children were chosen based on previous data collected as part of a large collaboration involving the school system in Houston, Texas. To provide children with a set of words that would be challenging but within their reading range, each child was given one of two lists (each of which contained 82 words): an "easy list" (given to children who scored in the bottom half of our sample on the WRAT) or a "hard list" (given to children who scored in the top half of our sample on the WRAT). Characteristics of the words in the easy list and hard list are provided in Appendix A.

\section{Session 3: Self-teaching day (context vs. isolation)}

One week later, words that children were unable to read correctly on the pretest (the self-teaching set) were presented to them, half in two-sentence paragraph contexts ${ }^{2}$ and half in isolation. Words were assigned randomly to each condition for each child. Contextualized and isolated words were presented in random order, such that a child might read two sentences in a row or might read a sentence followed by an isolated word. Both the two-sentence paragraphs containing target words and the isolated words were presented in black ink, in Arial font, on white paper. In the context condition, the experimenter read the paragraph aloud (except the last word) and followed along with his or her finger. The child was instructed to read the last word (which was bolded and underlined) after the rest of the paragraph had been read to him or her. In the isolation condition, the word was also presented bolded and underlined but with no supporting context; the experimenter simply pointed to the isolated word that was to be read. The child received no feedback on his or her performance in either condition. Whatever the child's response, the experimenter

\footnotetext{
2 The sentences used in the context condition had been normed previously with adult readers to ensure that they would provide a fairly predictable context. In a paper-and-pencil cloze task given to college students, the correct word was provided approximately $70 \%$ of the time $(M=66.8 \%, S D=31 \%)$. Most errors were higher frequency synonyms (e.g., pie for tart).
} 
simply said, "Okay, now let's go onto the next." For each word, the experimenter wrote down what the child said on a scoring sheet that was out of the child's view and recorded the child's utterances on a cassette tape.

\section{Session 4: Posttest}

One week after the self-teaching day, children read the words in their learning sets again, this time with all words presented in isolation (presentation order was randomized). Again, the words were presented underlined and in bold black ink on white paper. The experimenter wrote down each child's responses on a separate scoring sheet and recorded the child's responses on a cassette tape. The child received no feedback.

Scoring. In addition to calculating the number of words read correctly as a function of condition, a unique scoring method was used to help capture degrees of improvement ${ }^{3}$ in word learning. We used a four-point scale (0-3) of decoding accuracy to assess children's word reading during the self-teaching session (context vs. isolation) and on the posttest. We developed this scale during a previous study of children's word learning (Landi, Van Dyke, \& Perfetti, 2002). Children were given a 0 if they did not respond at all or said "I don't know," 1 point if they produced the first phoneme of the word, 2 points if they produced two or more phonemes of the word, and 3 points if they pronounced the word correctly. In the following Results section, all means for Sessions 3 and 4 are given both as average number correct and as an average out of 3 possible points (for all words read in each condition).

\section{Results}

\section{Reading assessment}

\section{WRAT}

The mean word reading score for the 23 children who completed the experiment was $45 \%$ of 15 total possible words $(S D=17 \%)$. To form two skill groupings, we used a median split to define a less skilled group of 11 children ( 6 girls and 5 boys) with a mean reading score on the WRAT of $29 \%(S D=6 \%)$, a mean reading grade of 0.6 , and a mean age of 6.60 years $(S D=0.53$ year). The more skilled group was composed of 12 children ( 8 girls and 4 boys) with a mean reading score on the WRAT of $59 \%(S D=5 \%)$, a mean reading grade of 1.8 , and a mean age of 7.02 years $(S D=0.69$ year). There was no significant correlation between WRAT score and children's age, $r^{2}=.10, p>.50$, and there was no significant difference in age between the skill groups, $t(21)=1.3, p>.10$.

\section{Nonword reading}

The mean nonword reading score for the nonword reading test was $41 \%(S D=25 \%)$ correct. Nonword reading was highly correlated with WRAT word reading, $r^{2}=.69$, $p<.01$. The high correlation between WRAT score and nonword reading confirmed that the WRAT provided a good measure of decoding ability. Because of this high correlation,

\footnotetext{
${ }^{3}$ Comparing points in addition to number correct was also important for comparing skill group differences because less skilled readers tended to have more words in their self-teaching sets; despite our attempt to give the children equally challenging words, less skilled readers still read fewer words correctly. See Tables 1 and 2.
} 
we chose to report findings based on just one split: WRAT score. All skill effects reported in this article are based on the WRAT score median split discussed above. ${ }^{4}$

\section{Session 2: Pretest}

The average number of words read incorrectly that would go on to be read throughout the rest of the experiment was 33 words ( $S D=14$ words), more skilled mean $=27$ $(S D=13)$, less skilled mean $=39(S D=14)$.

\section{Session 3: Self-teaching day}

To assess the effects of context on initial reading, results were subjected to a repeatedmeasures analysis of variance (ANOVA) with average reading score (0-3) as a dependent variable, isolation or context self-teaching condition as an independent variable, and reading skill as an independent between-subjects variable. The ANOVA revealed a main effect of self-teaching type. All children read words significantly better in context than in isolation, $F(1,21)=64.80, p<.001$ (average out of 3 possible points), regardless of skill level, and read significantly more words in context than in isolation, $F(1,21)=92.00, p<.001$, regardless of skill level (Table 1). This finding confirms previous findings of contextual facilitation during reading (Archer \& Bryant, 2001; Stanovich \& West, 1983). There was also a main effect of skill level, $F(1,21)=4.52, p<.05$, with more skilled readers outperforming less skilled readers (based on average score out of 3 possible points), but there was no main effect of skill when number correct was compared $(p>.10)$. The fact that there was no difference in the number of words read (in fact, less skilled readers actually read more words correctly [Table 1]) is likely due to the fact that less skilled readers had more words on average in their learning sets because they read more words incorrectly on the pretest. There were no other main effects or interactions.

\section{Session 4: Posttest}

To assess effects of context on later reading and on word retention, the posttest results include two different measures: word reading and word retention/learning. The word reading analyses compare the "raw" scores on the posttest (both number correct and average out of 3 ) as a function of whether the words were read in context or in isolation during the self-teaching session. Because this score confounds initial performance with retention, it cannot be interpreted as a learning measure. The word retention measure is conditionalized on the self-teaching day performance on the word and is a measure of how well children maintained a word representation as a function of whether they learned it in context or in isolation. That is, given a word initially unknown but read correctly during the self-teaching session, what was its fate on the posttest?

Word reading analysis. Results were subjected to a repeated-measures ANOVA with average reading score as the dependent variable (both number correct and average out of 3 ), self-teaching condition (isolation or context) as an independent variable, and reading skill as a between-subjects independent variable. The ANOVA revealed a main effect of skill level when average out of 3 possible points was used as the dependent variable, $F(1,21)=5.40, p<.05$, with more skilled readers outperforming less skilled readers, but not

\footnotetext{
${ }^{4}$ All of the skill comparisons reported here were also compared using a median split on nonword reading score, and the results did not differ.
} 
Table 1

Word reading and retention means expressed as numbers read correctly and as scores out of 3 possible points: Experiment 1

\begin{tabular}{|c|c|c|c|c|c|c|c|c|c|c|}
\hline & \multicolumn{4}{|c|}{ Self-teaching day reading } & \multicolumn{4}{|c|}{ Posttest reading } & \multicolumn{2}{|c|}{ Posttest retention } \\
\hline & \multicolumn{2}{|l|}{ Context } & \multicolumn{2}{|l|}{ Isolation } & \multicolumn{2}{|l|}{ Context } & \multicolumn{2}{|l|}{ Isolation } & \multirow[t]{2}{*}{ Context (\%) } & \multirow[t]{2}{*}{ Isolation $(\%)$} \\
\hline & $\begin{array}{l}\text { Average } \\
\text { number }\end{array}$ & $\begin{array}{l}\text { Average/3 } \\
\text { points }\end{array}$ & $\begin{array}{l}\text { Average } \\
\text { number }\end{array}$ & $\begin{array}{l}\text { Average/3 } \\
\text { points }\end{array}$ & $\begin{array}{l}\text { Average } \\
\text { number }\end{array}$ & $\begin{array}{l}\text { Average/3 } \\
\text { points }\end{array}$ & $\begin{array}{l}\text { Average } \\
\text { number }\end{array}$ & $\begin{array}{l}\text { Average/3 } \\
\text { points }\end{array}$ & & \\
\hline $\begin{array}{l}\text { More skilled } \\
\quad(n=11)\end{array}$ & $11.18(4.80)$ & $2.79(0.29)$ & $5.25(3.40)$ & $2.29(0.21)$ & $6.90(3.90)$ & $2.44(0.32)$ & $5.50(2.30)$ & $2.21(0.48)$ & $60(23)$ & $83(18)$ \\
\hline $\begin{array}{l}\text { Less skilled } \\
\quad(n=12)\end{array}$ & $15.40(4.80)$ & $2.57(0.35)$ & $4.50(1.60)$ & $1.97(0.63)$ & $5.40(3.10)$ & $1.95(0.52)$ & $5.10(3.70)$ & $1.80(0.68)$ & $36(21)$ & $57(24)$ \\
\hline
\end{tabular}

Note. Standard deviations are in parentheses. 
when average number of words read correctly was used ( $p>.10)$; again, this difference was most likely due to the asymmetry in the number of words in the two groups. There was no effect of self-teaching condition on posttest performance based on average score out of 3, $F(1,21)=3.85, p>.05$, or on number of words read, $F(1,21)=1.60, p>.10$ (Table 1$)$. There were no other main effects or interactions.

Word retention analysis. To determine whether children retained knowledge of the words they read during self-teaching, we conducted a conditionalized analysis using only the words that were read correctly during the self-teaching session. To measure this outcome, we calculated a percentage retained score by dividing the number of correct responses on the posttest by the number of correct responses during the self-teaching for each condition. For example, if five words were read correctly initially in context (during self-teaching) but only three of those same words were read correctly on the posttest, the child received a retention score of $60 \%$ for the context condition.

Retention scores were subjected to a repeated-measures ANOVA with average percentage retained score as the dependent variable, self-teaching condition (isolation or context) as an independent variable, and reading skill as a between-subjects independent variable. The results indicated that children retained significantly more words learned in isolation $(M=69 \%)$ than words learned in context $(M=47 \%), F(1,21)=13.59, p<.001$ (Table 1$)$. There was also a main effect of skill, $F(1,21)=10.60, p<.01$, with more skilled readers showing greater overall retention than less skilled readers. There were no other main effects or interactions.

\section{Discussion}

Our results from Experiment 1 confirm previous findings of facilitated word reading in context. Interestingly, the results also demonstrate a clear benefit on word retention if words were learned in isolation rather than in sentence context. This effect of context occurred for both more skilled and less skilled readers. Thus, our conclusion is that context helps reading but that isolated word learning leads to better word retention. These findings go beyond those of Archer and Bryant (2001) and of Landi and colleagues (2002), who found no positive effect of context over isolation, and call into question claims that suggest better word learning from in context encounters (Goodman, 1970).

We believe that the benefit of learning a new word form in isolation is caused by increased attention to the word's orthographic and phonological representations that is necessary for encoding. When beginning readers read words in context, they may fail to attend sufficiently to orthographic and phonological features of the words and instead rely on context to bolster their reading of unfamiliar words.

One concern about our Experiment 1 findings is that we failed to find the predicted interaction with reading skill. It is likely that the difference between our skill groups was not large enough to produce such an interaction. Although we found significant differences throughout the experiment between more skilled and less skilled readers, the size of this difference was rather small (typically 0.30 out of 3 possible points). Thus, the use of a relatively homogeneous population with few very poor readers might not have provided us with enough skill variance to detect an interaction. Furthermore, it is possible that our "one trial learning" design did not provide enough encounters with individual words and that larger differences and potential interactions might show up by including more learning trials. Therefore, Experiment 2 was designed to address this factor by including kindergartners, in 
addition to first and second graders, to increase our skill variance. Furthermore, to increase our overall sample size and keep a greater number of participants in the experiment until completion, we made our testing schedule more flexible (e.g., coming back to the school to retest children who missed one of the sessions). We also included more self-teaching opportunities (children saw all words three times during self-teaching) to allow for more word learning experiences and thus to increase the number of learned words in our final analysis.

Another potential question that arises is the extent to which our findings would generalize to learning across multiple contexts. Our findings from Experiment 1 compared isolated word learning with learning only in one particular context; however, in real learning situations, children encounter words in multiple contexts, and this multicontext learning may provide more flexible representations (i.e., less context dependent). To test this possible difference in Experiment 2, we included a multicontext self-teaching condition in which children saw a subset of words in three different contexts.

\section{Experiment 2}

Experiment 2 examined word retention in more skilled and less skilled readers as a function of how they learned the words: in a single context, in three different contexts, or in isolation. Furthermore, all children had three encounters (increased from one encounter in Experiment 1) with each word regardless of condition during the self-teaching session.

\section{Method}

\section{Participants}

The original sample consisted of 83 kindergartners, first graders, and second graders from the same school where data were collected for Experiment 1. The mean age was 6.50 years $(S D=1.00$ year). Of the original 83 children, 36 did not make it through to the final phase of the experiment because they read above the second-grade level, read too far below the first-grade level, or did not complete the experiment due to absences during the testing period. A total of 47 kindergartners, first graders, and second graders remained in the experiment until completion ( 25 girls and 22 boys, mean age $=6.32$ years, $S D=0.90$ year).

\section{Procedure}

The procedure for Experiment 2 was very similar to the procedure for Experiment 1. As in the first experiment, each child was tested individually in four separate sessions; however, we made several changes within each session. Changes are noted in the session descriptions that follow.

\section{Session 1: Assessment}

Each child's reading ability was assessed with an abbreviated version of the word reading portion of the WRAT. In this experiment, a longer version of the WRAT (30 items) was given to each child to avoid any potential ceiling effects. Because of the high correlations between WRAT score and nonword reading in Experiment 1, nonword reading was not tested. 


\section{Session 2: Pretest}

As in Experiment 1, the lists of words given to each child were designed to be just slightly above his or her reading ability to increase the number of unknown words that could potentially be learned during the course of the experiment. The two word lists used (easy and hard) were the same as those used in Experiment 1, and each contained 82 words (for details on the words in each list, see Appendix A).

\section{Session 3: Self-teaching day}

During the second session, all words that each child was unable to read in isolation were identified (the self-teaching set). For the current experiment, we added an additional multicontext condition (using three different contexts). For this condition, children saw a given word in three different supportive contexts instead of just one supportive context. Furthermore, during self-teaching, all children read all words, whether in context or in isolation, three nonconsecutive times instead of just once during self-teaching. That is, children were required to read all of the words they did not read correctly on the pretest, either in context three times, in three different contexts (the first two-sentence context was the same as the one used in the one context condition) or in isolation three times. Condition order was randomized.

\section{Session 4: Posttest}

During the fourth session, children read all words in the self-teaching set once more in isolation. Words were presented in random order.

Scoring. As in Experiment 1, we calculated an average out of 3 possible points for each condition in addition to calculating the total number of words read correctly for each condition. Children were given a 0 if they did not respond at all or said "I don't know," 1 point if they produced the first phoneme of the word, 2 points if they produced two or more phonemes of the word, and 3 points if they pronounced the word correctly.

\section{Results}

\section{Skill assessment}

\section{WRAT}

The average WRAT reading score for all 47 children was $22 \%$ out of 30 possible words correct. ${ }^{5}$ Children were split according to their WRAT scores (median split) into two skill groups: a more skilled group composed of 21 children (mean WRAT score $=37 \%$, $S D=1 \%$, mean reading grade $=2.5$, mean age $=6.83$ years, $S D=0.78$ year) and a less skilled group composed of 26 children (mean WRAT score $=12 \%, S D=0.7 \%$, mean reading grade $=0.4$, mean age $=5.90$ years, $S D=0.94$ year). For this experiment, WRAT scores were correlated with age, $r^{2}=.50, p<.05$, and unlike the groups in Experiment 1 , the two

\footnotetext{
5 In Experiment 1, we cut off children at 15 words; in Experiment 2, we raised the cutoff to 30 possible words to increase potential skill variability that we may have missed in Experiment 1. Only two children in Experiment 2 read more than 15 words correctly. To equate the WRAT scores with those presented in Experiment 1 (for comparison), which was calculated as percentage correct out of 15 total possible words, instead of percentage correct out of 30 total possible words, we can multiply the numerator by 2. More skilled and less skilled readers would have means of 0.74 and 0.24 , respectively.
} 
groups in Experiment 2 differed significantly in age, $t(45)=3.6, p<.05$. This difference between the two experiments was due to the increased age range included in the second experiment. Possible effects of this age difference are discussed later.

\section{Session 2: Pretest}

On average, children read $40.60(S D=19.35)$ words incorrectly, more skilled mean $=25$ $(S D=10)$, less skilled mean $=52(S D=15)$. These words became the self-teaching set and were used during Sessions 3 and 4.

\section{Session 3: Self-teaching day word reading}

A repeated-measures ANOVA examined the effect of self-teaching condition on the first encounter with each word. The average score out of 3 possible points and the total number of words read correctly were the dependent variables, self-teaching condition (context or isolation) was an independent variable, and skill was a between-subjects independent variable. Self-teaching day results mirrored the findings from Experiment 1. Children were better at reading previously unknown words if they were in a sentence context or read in three different contexts than if they were read in isolation, $F(2,70)=9.10, p<.01$, based on average score out of 3 possible points, and they read more words in context and in three different contexts than in isolation, $F(2,70)=70.00, p<.01$. There was no difference between the two context conditions, based on average score out of 3 possible points, or on number of words read, $F<1$. Furthermore, a main effect of skill confirmed that more skilled readers outperformed less skilled readers, $F(1,45)=14.00, p<.01$, based on average score out of 3 possible points, but because of uneven list sizes (as in Experiment 1), this difference did not hold when numbers of items read were compared, $F<1 .{ }^{6}$ There were no other significant main effects or interactions (Table 2).

\section{Session 4: Posttest}

Posttest word reading. A repeated-measures ANOVA compared average posttest word reading score out of 3 possible points as a function of self-teaching condition (isolation, one context, or three contexts) and reading skill. As in Experiment 1, there was no difference in word reading performance on the posttest between words that were read in context during self-teaching (for either the one context condition or the three context condition) compared with words that were read in isolation during self-teaching, when average scores out of 3 possible points were compared $(p>.10)$ or when average numbers of words read were compared $(F<1)$. There was, however, a main effect of skill, with more skilled readers outperforming less skilled readers, $F(1,45)=51.00, p>.01$ (average score out of 3 possible points), and $F(1,45)=4.16, p<.05$ (average number read correctly). There were no other significant main effects or interactions (for means and standard deviations, see Table 2).

Posttest word retention. For the retention analysis, only 37 readers (20 less skilled [10 boys and 10 girls] and 17 more skilled [10 boys and 7 girls]) were included. Of those who could not be included, 6 kindergartners in the less skilled condition did not get at least one word right in each condition during self-teaching and therefore could not be included in the conditional analysis, and 4 more skilled readers did not have enough words in each

\footnotetext{
${ }^{6}$ In the number analysis, less skilled readers actually read more words correctly than did skilled readers because they had more words on their lists overall.
} 
Table 2

Word reading and retention means expressed as numbers read correctly and as scores out of 3 possible points: Experiment 2

\begin{tabular}{|c|c|c|c|c|c|c|c|c|c|c|c|c|c|c|c|}
\hline & \multicolumn{6}{|c|}{ Self-teaching day reading } & \multicolumn{6}{|c|}{ Posttest Reading } & \multicolumn{3}{|c|}{ Posttest retention } \\
\hline & \multicolumn{2}{|l|}{ Context } & \multicolumn{2}{|c|}{ Context $3 \times$} & \multicolumn{2}{|l|}{ Isolation } & \multicolumn{2}{|l|}{ Context } & \multicolumn{2}{|c|}{ Context $3 \times$} & \multicolumn{2}{|l|}{ Isolation } & \multirow{2}{*}{$\begin{array}{l}\text { Context } \\
-(\%)\end{array}$} & \multirow{2}{*}{$\begin{array}{l}\text { Context } \\
3 \times(\%)\end{array}$} & \multirow{2}{*}{$\begin{array}{l}\text { Isolation } \\
(\%)\end{array}$} \\
\hline & $\begin{array}{l}\text { Average } \\
\text { number }\end{array}$ & $\begin{array}{l}\text { Average/ } \\
3 \text { points }\end{array}$ & $\begin{array}{l}\text { Average } \\
\text { number }\end{array}$ & $\begin{array}{l}\text { Average/ } \\
3 \text { points }\end{array}$ & $\begin{array}{l}\text { Average } \\
\text { number }\end{array}$ & $\begin{array}{l}\text { Average/ } \\
3 \text { points }\end{array}$ & $\begin{array}{l}\text { Average } \\
\text { number }\end{array}$ & $\begin{array}{l}\text { Average/ } \\
3 \text { points }\end{array}$ & $\begin{array}{l}\text { Average } \\
\text { number }\end{array}$ & $\begin{array}{l}\text { Average/ } \\
3 \text { points }\end{array}$ & $\begin{array}{l}\text { Average } \\
\text { number }\end{array}$ & $\begin{array}{l}\text { Average/ } \\
3 \text { points }\end{array}$ & & & \\
\hline $\begin{array}{l}\text { More } \\
\quad \text { skilled } \\
\quad(n=26)\end{array}$ & $7.4(3.5)$ & $2.8(3.5)$ & $6.4(2.5)$ & $2.7(0.66)$ & $3.9(1.7)$ & $2.63(0.17)$ & $4.2(2.1)$ & $2.43(0.10)$ & $4.5(2.2)$ & $\begin{array}{l}2.28 \\
(0.10)\end{array}$ & $4.4(1.9)$ & $\begin{array}{l}2.45 \\
(0.10)\end{array}$ & $67(5)$ & $65(0.5)$ & $80(7)$ \\
\hline $\begin{array}{l}\text { Less } \\
\quad \text { skilled } \\
\quad(n=21)\end{array}$ & $10.6(3.4)$ & $2.2(0.12)$ & $11.6(3.5)$ & $1.9(0.46)$ & $3.7(2.4)$ & $1.85(0.15)$ & $2.5(1.6)$ & $1.34(0.09)$ & $2.1(1.8)$ & $\begin{array}{l}1.31 \\
(0.10)\end{array}$ & $3.2(2.5)$ & $\begin{array}{l}1.3 \\
(0.10)\end{array}$ & $24(4)$ & $30(5)$ & $74(6)$ \\
\hline
\end{tabular}

Note. Standard deviations are in parentheses. 
condition, most likely because they began with too few unknown words at the start of the experiment.

A repeated-measures ANOVA compared average percentage of words retained as a function of self-teaching condition and reading skill. The results confirmed the effect of context found in Experiment 1. Words learned in isolation were more likely to be retained than were words learned in either context condition, $F(2,70)=21.00, p<.001$. There was also a main effect of skill, $F(2,70)=36.00, p<.001$. Furthermore, there was a significant interaction between skill and word retention as a function of context, $F(2,70)=6.70$, $p<.01$. Pairwise comparisons revealed that the isolated condition had significantly higher retention than the single context condition for less skilled readers, $t(19)=6.6, p<.001$, but not for more skilled readers, $t(16)=1.3, p>.10$. The same pattern held when we compared retention in the isolated condition with retention in the three different context conditions. The difference was significant for less skilled readers, $t(19)=5.8, p<.01$, but not for more skilled readers, $t(16)=1.3, p>.10$. There was no difference in word retention between the two context conditions for less skilled readers, $t(19)=1.5, p>.10$, or for more skilled readers, $t(16)=0.4, p>.10$ (Table 2 ).

Thus, the increased word retention in the isolated condition compared with the context conditions was greater for less skilled readers than for more skilled readers. In fact, a regression analysis showed a linear relation between skill and benefit from isolated learning, $r^{2}=.37, p<.001$. This interaction provides critical evidence for our hypothesis that context can affect reading and learning differently (Fig. 1). To investigate the relative contribution of age to our skill effect, we used a hierarchical regression, first entering age, followed by skill in a second regression analysis. The results showed that age was not a significant predictor of retention in isolated word learning and that it had no effect on the relation between skill and increased retention in isolated word learning.

\section{Discussion}

As in Experiment 1, we found that context benefited readers reading new words, a finding consistent with a large body of existing data. Importantly, Experiment 2 also confirmed our finding that isolated word learning conditions lead to better word retention than do contextualized word learning conditions. Furthermore, our finding of increased retention for words learned in isolation persisted when students learned words in three different

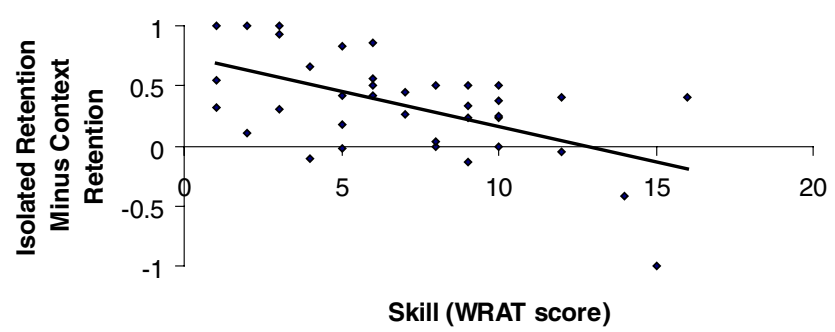

Fig. 1. Scatter plot showing the correlation between skill and benefit from isolated word learning and the linear relation between skill level and benefit on word retention when words were learned in isolation relative to in context. As skill level increased, children showed a reduction in the amount that they benefited from isolated learning relative to contextualized learning. 
contexts and when they learned over three learning trials, providing evidence that our findings generalize to a more naturalistic learning situation.

In Experiment 2, we found a significant interaction between reading ability (as measured by WRAT reading score) and retention. Less skilled readers benefited from learning in the isolated condition to a greater extent than did more skilled readers. Furthermore, a regression analysis detected a linear relation between skill level and benefit from isolated learning. This relation was not mediated by age. The greater number of self-teaching trials and larger skill difference between the groups in Experiment 2 may have allowed this critical interaction to emerge. These findings, along with the findings from Experiment 1, support our hypothesis that semantic context is beneficial for word reading but can lead to a lack of attention to a word's graphemic and phonemic information and hence only weak encoding of word representations. The interaction between skill and context in word retention lends support to our account. Readers with the most impoverished word representations are likely to rely more on semantic information when reading unknown words and hence pay less attention to words' graphemic and phonemic information; thus, their representations remain impoverished - a "poor get poorer" scenario. More skilled readers' benefits from isolated learning, relative to contextualized learning, are smaller because, as better decoders, they need not focus all of their attention and resources on decoding.

Despite the corroborating evidence from our two experiments, one alternative explanation for our findings seems possible. Because each child saw a different list of words in our experiments, stimulus differences between the isolated and contextualized word reading conditions may have contributed to our findings. For example, the items that were read correctly in the isolated conditions might have been easier to read than the items that were read correctly in the context conditions (and hence isolated words were easier to retain). We attempted to control for this potential confound by making sure that all word forms were unknown to readers at the beginning of the experiment; however, it was still possible that a particular word may have been easier to acquire. To provide additional assurance that this was not the case, we tried to control for "word difficulty." To do this, we reviewed the characteristics of the words read correctly during self-teaching and of all the words read correctly on the posttest. More specifically, we compared the difficulty of the words read correctly in each condition by comparing their frequency, their number of letters, the percentage of words with complex codas (e.g., most), and the percentage of words with complex onsets (e.g., stay). The only significant difference between the words that were read correctly during self-teaching and the words that were retained (posttest) between the isolated and context conditions was on the complex coda measure. A one-way ANOVA revealed a significant difference between the groups on the percentage of words with complex codas in training $(p=.03)$ and on the posttest $(p=.04)$. There were no other significant differences between the stimuli read correctly during self-teaching and those read correctly on the posttest (Appendix A). To control for this possible confound (more difficult codas in the context conditions), we covaried out the effect of complex coda difficulty ${ }^{7}$ and reran our repeated-measures ANOVA. Our main effect of context was still significant, $F(2,70)=24.60, p<.01$, and our interaction between context and skill also was still significant, $F(2,70)=3.39, p<.05$.

\footnotetext{
${ }^{7}$ To covary out the effects of coda complexity, we regressed on complex coda and retention for each condition and then multiplied the resulting beta weights by each participant's retention score and recomputed our repeatedmeasures ANOVA.
} 
We attempted to further examine word difficulty by running an items analysis on a subset of our data. By carrying out an items analysis using a set of words that occurred in each of the self-teaching conditions, we were able to add a post hoc control for word difficulty. A total of 27 of our words occurred in all conditions at least once across participants, and we conducted a repeated-measures ANOVA on just these items (collapsed across skill). This ANOVA revealed a main effect of context, $F(1,52)=4.49, p<.01$. Words learned in isolation showed greater average retention scores $(M=2.60$, $S D=0.47)$ than did words learned in context $(M=2.34, S D=0.74)$ or words learned in three different contexts $(M=1.50, S D=0.74)$. Thus, our effect of better retention for words learned in isolation compared with words learned in context remained even when the words in each self-teaching condition were the very same words. Given this result, and given our finding of no significant effect of word difficulty level across words read correctly, it is unlikely that our findings were due simply to words read correctly in isolation being easier than those read in context.

\section{General discussion}

We suggest that the source of our effects lies in the focus of attention (and hence direction of resources), specifically the degree to which readers are focused on orthographic and phonological mappings of a word while they decode it. The semantic information provided by sentence context provides top-down support for word reading that allows readers' focus to be drawn away from word decoding. Without enough focus, readers fail to encode the appropriate orthographic and phonological information. This is true for both more skilled and less skilled readers, but it is more relevant to less skilled readers because they have a greater need to focus on letter-sound processing of new words due to their weaker decoding skills.

This explanation requires a few assumptions about the development of reading skill. Primarily, we must assume that some attention to word forms is essential for children to come to establish these forms as representations with orthographic, phonological, and semantic components (Reitsma, 1983; Share, 1995). In addition, we must assume that more skilled readers need not focus on words' orthographic and phonological features to the same degree to encode new representations. If both of these assumptions are met, context should have differential effects on word identification and on retention, and these differences should be larger for less skilled readers. We also predict that as decoding skills increase and as more words acquire specific orthographic representations, a more effective distribution of attention and resources will lead to a context effect that is positive for reading and neutral for retention. This hypothesis is supported by our regression analysis on the amount of benefit observed from learning in isolation that showed that learning in context and learning in isolation produced approximately equal levels of retention in the most highly skilled readers in our sample. These results are also consistent with other results demonstrating that more skilled readers are better able to use context but that less skilled readers show greater bootstrapping from reading in context compared with reading in isolation (Perfetti \& Roth, 1981).

Our conclusions are consistent with Share's phonological recoding and self-teaching hypothesis (Cunningham et al., 2002; Share, 1995, 1999). This hypothesis posits that the primary and most successful way in which children acquire new word representations is via 
a reciprocal relation between a word's orthography and its phonology. The self-teaching mechanism involves children's ability to combine their awareness of letter-sound correspondences with their ability to retrieve word-specific orthographic information. For example, to read the word jail, children would combine their ability to partially sound out the letters with their knowledge that the word begins with a $j$. This process is most successful when readers are tackling material of which they have at least partial knowledge (i.e., skill-appropriate words) and when children are focusing on word reading rather than on integration of text meaning. This last point is crucial to our hypothesis. If contextual information is available, children might not need to use their implicit self-teaching skills to decode new words. Instead, the context may provide semantic information that allows evasion of a full grapheme-phoneme mapping.

Our results are also consistent with findings in the literature showing that learning tasks that are more difficult, or that require more attention to difficult-to-master material, can produce better retention. For example, Bruck and Trieman (1992) found that children who used a more simple rhyme analogy strategy to help with word learning did not retain as many of the newly learned words as did children who used a more difficult vowel decoding strategy. They found that using rhyme information during self-teaching was more helpful than simply using the available grapheme-phoneme correspondences on which they had been trained. However, like our context effect, this advantage reversed on later tests when an advantage for self-teaching with grapheme-phoneme correspondences (especially for vowels) emerged.

One instructional implication of our findings needs to be addressed cautiously. The implication from our experiments is that reading words in isolation can increase the number of words children can read at a later time relative to reading words in context. The conditions that produce superior learning from isolated words are yet to be fully specified, and any specific recommendation would be premature. Although we found superior retention for words learned in isolation, the overall numbers of words read on the posttest as a function of self-teaching condition did not differ. Further research will be needed to determine whether the findings indicated by our retention measure or by our measure of overall number of words read correctly will predict the outcome of longterm learning more accurately. Furthermore, if the probability of retaining words is higher for words acquired during isolation reading than for words acquired during in context reading, simply presenting more words in context might make up for this probability difference. However, we do think that there is a reasonable and practical implication that young readers, while they are in the early stages of learning to read many new words, can benefit from reading that draws attention to word form and word decoding (e.g., the fingerpoint reading technique used by Ehri \& Sweet, 1991). We do not, however, suggest that isolated word learning should replace learning words in stories; rather, we suggest that it should complement such learning, especially for less skilled and beginning readers.

\section{Acknowledgments}

We thank Jillian Ketterer, Erik D. Reichle, Natasha Tokowicz, and Rebecca Sandak for their comments and editorial assistance. We also thank the Falk School, along with Laurie Williams and Marian Volmer, for assisting with our data collection. This research was 
supported in part by grants from the U.S. Department of Education, Institute of Education Sciences (Grant R305G020006A), and by the National Science Foundation (Interagency Education Research Initiative [IERI] program, Grant 9979968).

\section{Appendix A}

Characteristics of pretest words (means) for Experiments 1 and 2

\begin{tabular}{|c|c|c|c|c|}
\hline & $\begin{array}{l}\text { Frequency (Kucera } \\
\text { and Francis, 1967) }\end{array}$ & $\begin{array}{l}\text { Number of } \\
\text { letters }\end{array}$ & $\begin{array}{l}\text { Percentage } \\
\text { complex coda }\end{array}$ & $\begin{array}{l}\text { Percentage } \\
\text { complex onset }\end{array}$ \\
\hline Easy & 123 & 4.7 & 35 & 41 \\
\hline Hard & 55 & 6.1 & 37 & 48 \\
\hline \multicolumn{5}{|c|}{$\begin{array}{l}\text { Characteristics of words read correctly on self-teaching day by condition (means) and } \\
\text { results from a one-way ANOVA comparing condition means }\end{array}$} \\
\hline & $\begin{array}{l}\text { Frequency (Kucera } \\
\text { and Francis, 1967) }\end{array}$ & $\begin{array}{l}\text { Number } \\
\text { of letters }\end{array}$ & $\begin{array}{l}\text { Percentage } \\
\text { complex coda }\end{array}$ & $\begin{array}{l}\text { Percentage } \\
\text { complex onset }\end{array}$ \\
\hline Isolation & 104 & 4.9 & 34 & 35 \\
\hline Context $1 \times$ & 109 & 5.3 & 46 & 32 \\
\hline Context $3 \times$ & 101 & 5.2 & 46 & 30 \\
\hline$p$ value & $n s$ & $n s$ & .03 & $n s$ \\
\hline
\end{tabular}

Characteristics of words read correctly on posttest by condition (means) and results from a one-way ANOVA comparing condition means

\begin{tabular}{lllll}
\hline & $\begin{array}{l}\text { Frequency (Kucera } \\
\text { and Francis, 1967) }\end{array}$ & $\begin{array}{l}\text { Number } \\
\text { of letters }\end{array}$ & $\begin{array}{l}\text { Percentage } \\
\text { complex coda }\end{array}$ & $\begin{array}{l}\text { Percentage } \\
\text { complex onset }\end{array}$ \\
\hline Isolation & 123 & 4.9 & 31 & 40 \\
Context $1 \times$ & 170 & 5.2 & 48 & 29 \\
Context $3 \times$ & 147 & 5.2 & 46 & 32 \\
$p$ value & $n s$ & $n s$ & .04 & $n s$ \\
\hline
\end{tabular}

\section{References}

Archer, N., \& Bryant, P. (2001). Investigating the role of context in learning to read: A direct test of Goodman's model. British Journal of Psychology, 92, 579-591.

Bruck, M., \& Trieman, R. (1992). Learning to pronounce words: The limitations of analogies. Reading Research Quarterly, 27, 375-387.

Cunningham, A. E., Perry, K. E., Stanovich, K. E., \& Share, D. L. (2002). Orthographic learning during reading: Examining the role of self-teaching. Journal of Experimental Child Psychology, 82, 185-199.

Ehri, L. C. (1991). Development of the ability to read words. In R. Barr, M. L. Kamil, P. D. Mosenthal, \& P. D. Pearson (Eds.), Handbook of reading research (Vol. 2, pp. 383-417). New York: Longman.

Ehri, L. C., \& Sweet, J. (1991). Fingerpoint-reading of memorized text: What enables beginners to process the print? Reading Research Quarterly, 26, 442-462.

Ehri, L. C., \& Wilce, L. S. (1985). Movement into reading: Is the first stage of printed word learning visual or phonetic? Reading Research Quarterly, 20, 163-179.

Goodman, K. S. (1970). Reading: A psycholinguistic guessing game. In H. Singer \& R. B. Rudell (Eds.), Theoretical models and processes of reading (pp. 259-271). Newark, DE: International Reading Association.

Kucera, H., \& Francis, W. N. (1967). Computational analysis of present-day American English. Providence, RI: Brown University Press. 
Landi, N., Van Dyke, J., \& Perfetti, C. A. (2002, June). The causes and consequences of predictability. Poster presented at the annual meeting of the Society for the Scientific Study of Reading, Chicago.

Nation, K., \& Snowling, M. J. (1998). Individual differences in contextual facilitation: Evidence from dyslexia and poor reading comprehension. Child Development, 69(4), 996-1011.

Perfetti, C. A. (1992). The representation problem in reading acquisition. In P. B. Gough, L. Ehri, \& R. Trieman (Eds.), Reading acquisition (pp. 145-174). Hillsdale, NJ: Lawrence Erlbaum.

Perfetti, C. A., \& Roth, S. (1981). Some of the interactive processes in reading and their role in reading skill. In A. Lesgold \& C. A. Perfetti (Eds.), Interactive processes in reading (pp. 269-297). Hillsdale, NJ: Lawrence Erlbaum.

Rayner, K., Foorman, B. R., Perfetti, C. A., Pesetsky, D., \& Seidenberg, M. S. (2001). How psychological science informs the teaching of reading. Psychological Science in the Public Interest, 2, 31-74.

Reitsma, P. (1983). Printed word learning in beginning readers. Journal of Experimental Child Psychology, 36, 321-339.

Roth, S. F., \& Perfetti, C. A. (1980). A framework for reading, language comprehension, and language disability. Topics in Language Disorders, 11, 15-27.

Schwantes, F., Boesl, S. L., \& Ritz, E. G. (1980). Children's use of context in word recognition: A psycholinguistic guessing game. Child Development, 51, 730-736.

Share, D. L. (1995). Phonological recoding and self-teaching: Sin qua non of reading acquisition. Cognition, 55, $151-218$.

Share, D. L. (1999). Phonological recoding and orthographic learning: A direct test of the self-teaching hypothesis. Journal of Experimental Child Psychology, 72, 95-129.

Stanovich, K. E., Nathan, R. G., West, R. F., \& Vala-Rossi, M. (1985). Children's word recognition in context: Spreading activation, expectancy, and modularity. Child Development, 56, 1418-1428.

Stanovich, K. E., \& West, R. F. (1983). On priming by sentence context. Journal of Experimental Psychology: General, 112, 1-36. 